\title{
MENGUKUR AKURASI QUERY PADA INTERFACE REPOSITORY MENGGUNAKAN USER INTERFACE (UI) DISCOVERY BERBASIS SOFTWARE AS A SERVICE (SAAS)
}

\author{
Shofiyatun Najah ${ }^{(1)}$, Muhammad Ainul Yaqin ${ }^{(2)}$, \\ Linda Salma Angreani ${ }^{(3)}$, Abd. Charis Fauzan ${ }^{(4)}$ \\ 1,2,3 Jurusan Teknik Informatika, Universitas Islam Negeri Maulana Malik Ibrahim \\ ${ }^{4}$ Program Studi Ilmu Komputer, Universitas Nahdlatul Ulama Blitar \\ Email: 1'shofiyatun.najah11@gmail.com, 2yaqinov@ti.uin-malang.ac.id, \\ ${ }^{3}$ linda@uin-malang.ac.id, ${ }^{4}$ abdcharis@unublitar.ac.id
}

Tersedia Online di

http://www.jurnal.unublitar.ac.id/ index.php/briliant

\begin{tabular}{l}
\hline Sejarah Artikel \\
\hline Diterima pada 24 April 2019 \\
Disetuji pada 26 April 2019 \\
Dipublikasikan pada 22 Mei 2019 \\
Hal. 206-214 \\
\hline
\end{tabular}

Kata Kunci:

User Interface (UI), discovery, Software as a Service, Interface Repository

\section{DOI:}

http://dx.doi.org/10.28926/briliant .v3i4.312

dan nilai presisi dalam presentase yang berbeda. Presentase pada model pencarian diperoleh sebesar 95\% dan pada model pencarian detail diperoleh sebesar $90 \%$. Perbedaan tersebut diperoleh karena pada pencarian detail terdapat beberapa dokumen tidak relevan yang ditemukan dan terjaring query, sehingga pada pencarian data menunjukkan hasil yang lebih relevan dan menunjukkan kemampuan sistem lebih baik.

\section{PENDAHULUAN}

SaaS (Software as a Service) merupakan model dimana aplikasi ditawarkan kepada klien sebagai sebuah service. Jika sebuah service disajikan kepada klien, klien tidak perlu merawat dan melakukan update pada aplikasi tersebut. Namun sebaliknya, apabila provider akan melakukan update pada aplikasi tersebut, maka klien hanya bisa mengikuti apa yang dilakukan oleh provider (Choudhary, 2007).

SaaS memiliki berbagai macam lapisan arsitektur yang bertujuan untuk memenuhi berbagai kebutuhan fungsional pada sebuah aplikasi. SaaS merupakan salah satu model pengiriman layanan perangkat lunak yang berfungsi untuk mengubah cara orang dalam membangun, menjual, membeli, dan menggunakan perangkat lunak (Kumar, 2014). Framework SaaS memiliki empat lapisan, yaitu 
lapisan data, lapisan servis, lapisan bisnis proses, dan lapisan UI. Lapisan UI merupakan lapisan yang berfungsi menyediakan interface antara sistem dan pengguna, sehingga memudahkan pengguna dalam mengubah tampilan aplikasi. Penelitian ini bertujuan untuk membantu pengguna dalam pencarian interface yang sesuai dengan aplikasi pengguna secara cerdas dan terotomasi. Langkah yang digunakan untuk mengatasi permasalahan tersebut yaitu dengan menggunakan pendekatan ontologi (Fauzan, Sarno, \& Ariyani, 2018).

Ontologi merupakan sebuah spesifikasi yang ekspisit dan terbaca oleh mesin dari suatu konseptualisasi (Gómez-pérez, Corcho, \& Madrid, 2002). Alat yang digunakan untuk mengembangkan aplikasi web semantic yaitu harus menyediakan layanan untuk mengakses, memvisulisasi, mengubah, dan menggunakan ontologi (Knublauch, Fergerson, Noy, \& Musen, 2004). Sesuai dengan pertumbuhan web ontologi saat ini, saah satu tugas yang menantang yaitu mencari ontologi yang diinginkan pengguna (Patel, Supekar, Lee, \& Park, 2003). Ontologi digunakan untuk proses pencarian. Hasil pencarian yang ditampilkan oleh sistem tidak hanya sesuai dengan kata kunci yang dimasukkan oleh pengguna melainkan juga kata kunci tersebut memiliki sinonim dan keterkaitan dengan katakata secara semantik di dalam ontologi. Pada lapisan GUI, ontologi UI dibangun untuk memberikan makna yang lebih luas dan membantu sistem komputer bekerja dengan cara yang lebih mudah.

Aplikasi SaaS memiliki beberapa lapisan arsitektur yaitu data layer, service layer, process layer, dan UI layer (Shao, 2011). Data layer dan service layer berfungsi sebagai lapisan yang menetapkan struktur data dan operasi untuk aplikasi. Procces layer yaitu lapisan yang berfungsi mengelola mekanisme service. UI layer yaitu merupakan lapisan GUI yang berfungsi untuk menyediakan interface antara sistem dan user dalam menerima input dari user dan menampilkan hasil kembali kepada user. UI yang tersedia memudahkan user untuk mengubah dan mengkonfigurasi tampilannya, termasuk menambahkan /mengubah/menghapus ikon, warna, font, judul, dan menu yang ada didalamnya. Cara untuk mengembangkan user interface agar menjadi peranan penting dalam sistem yaitu menggunaka User Interface Management System (UIMS).

User Interface Management System (UIMS) adalah sebuah mekanisme untuk proses memisahkan kode Graphic User Interface (GUI) dalam suatu program komputer. Tujuan dari UIMS yaitu menciptakan suatu cara agar bisa diperoleh interface yang konsisten yang memiliki tampilan untuk sejumlah aplikasi yang berbeda namun di dalam sistem yang sama.

Menurut Raymond E. Barber dan Henry C. Lucas, JR dalam workshopnya di Seattle pada tahun 1982 menjelaskan tentang pengembangan UI, dan UI diimplementasikan dengan menggunakan alat pemrograman tertentu dan terpisah dari kode aplikasi. User Interface Management Systems (UIMS) adalah mediator antara pengguna dan program aplikasi (Enderle \& Duce, n.d.). Agar aplikasi menjadi interaktif maka harus lebih memiliki pendukung dalam mengontrol aplikasi (eksternal control) daripada kode aplikasi (internal control)(Barber \& Lucas, 1983).

Menurut model Seeheim, UIMS memiliki tiga komponen (Dan R. Olsen, 1992). Komponen utamanya adalah control dialog. Control dialog yaitu komunikasi yang terjadi antara pengguna dan aplikasi. Struktur control dialog kemudian diubah menjadi sebuah urutan input yang dikirimkan ke model aplikasi 
user interface untuk mengeksekusi perintah dari sistem (Green, 1985). Presentation merupakan komponen yang bertanggungjawab terhadap interface yang mencakup output dan input yang tersedia bagi user.

RDF (Resource Description Framework) digunakan sebagai representasi komponen teknologi web semantik. RDF berfungsi untuk mendeskripsikan isi sebuah web. SPARQL merupakan komponen yang digunakan sebagai query untuk mengambil data yang tersimpan pada RDF. UI Discovery merupakan bagian penting dalam arsitektur web service. UDDI menyediakan sebuah standarisasi dan discovery ontologi UI untuk pencarian kata kunci. Proses discovery tersebut tidak dapat diketahui pada UI web service apabila dengan kata kunci yang berbeda melainkan memiliki arti yang sama. Pada proses pencarian kemiripan dapat dilihat berdasarkan label (label similarity), struktural (structural similarity), dan juga perilaku proses bisnis tersebut (behavioral similarity) (Fauzan, Sarno, Yaqin, \& Jamal, 2017) dan (Yaqin, Sarno, \& Fauzan, 2017). Penyelasaian masalah tersebut dapat diselesaikan dengan cara discovery sistem untuk mencocokkan query pada web service menggunakan ontologi. Pada penelitian ini mengajukan pendekatan anotasi interface repository menggunakan RDF Map sebagai ontologi dengan UI discovery. Agar UI discovery menjadi cerdas dan terotomasi maka dicoba menggunakan query SPARQL.

\section{METODE}

Data yang digunakan diperoleh dari penelitian sebelumnya yaitu tentang web service pada ERP Pondok Pesantren di bidang akademik. Data yang diolah yaitu file PHP yang berisi interface pada sebuah form. File tersebut kemudian diparsing untuk mengambil komponen interface. Berikut adalah blok diagram proses aplikasi UI discovery.

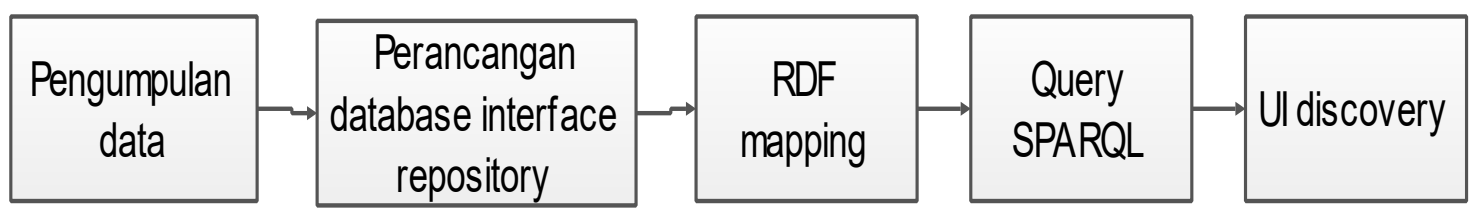

Gambar 1. Blok Diagram Metode Penelitian

\section{Pengumpulan Data}

Data yang digunakan yaitu berupa dokumen PHP. Dokumen PHP berisi interface dengan berbagai tag HTML seperti yang diilustrasikan pada gambar 2.

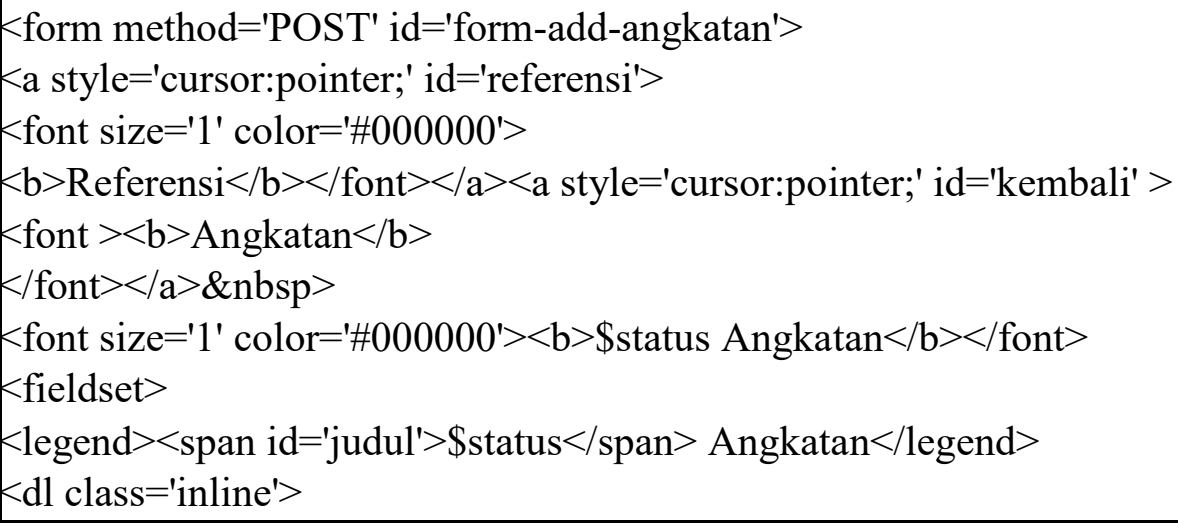




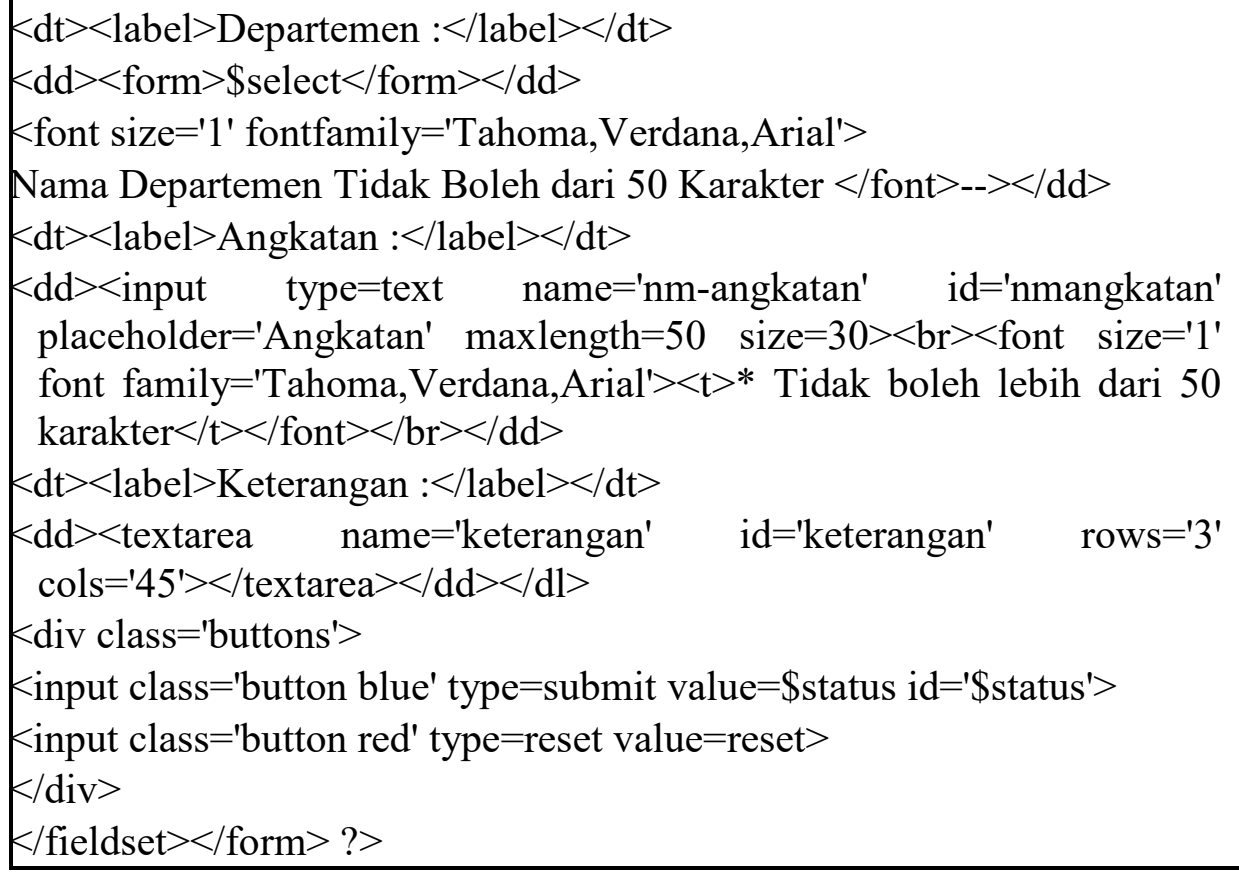

Gambar 2. Dokumen Interface

\section{Perancangan Database Interface Repository}

Data yang diolah yaitu dokumen PHP yang berisi interface pada sebuah form. Dokumen tersebut kemudian diparsing untuk diambil komponen interface. Setelah itu, merancang database dengan nama ui_repository yang berisi tabel form dan tabel komponen seperti pada gambar 3. Tabel form berfungsi untuk menyimpan identitas form yang berupa nama, lokasi file, dan source code atau isi dari form. Sedangkan, tabel komponen berfungsi untuk menyimpan data atribut elemen interface, yaitu nama komponen, dan id komponen.

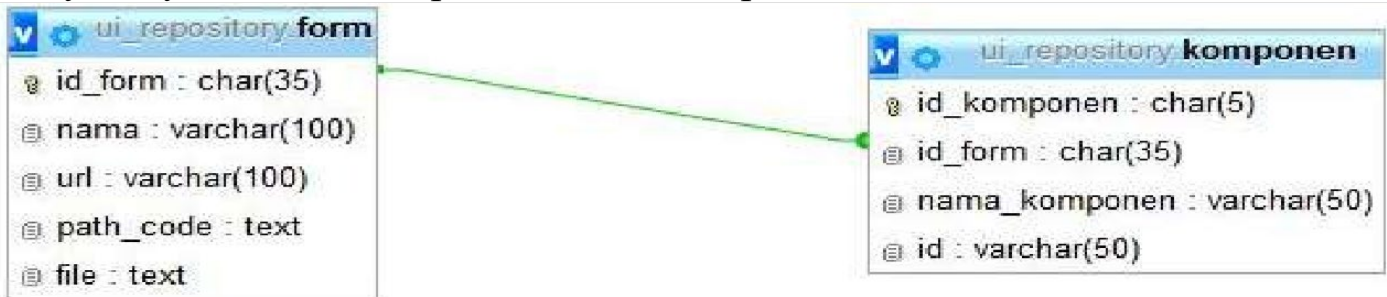

Gambar 3. Database Interface Repository

\section{RDF Map}

Saat ini, telah banyak data yang diformat dan disimpan dalam database relasional. Untuk menjadikannya format data web semantik, maka menggunakan RDF map. RDF map adalah suatu ontologi dari semantik web berfungsi sebagai perantara pengaksesan data pada repository. RDF map merupakan file mapping dari proses database yang telah degenerate. Berikut adalah RDF Map dari database ui_repository yang disimpan dalam format turtle seperti yang diilustrasikan pada seperti gambar 4 . 
@prefix map: <\#>.

@ prefix db: $<$.

@prefix vocab: $<$ vocab/> .

@ prefix rdf: <http://www.w3.org/1999/02/22-rdf-syntax-ns\#> .

@prefix rdfs: <http://www.w3.org/2000/01/rdf-schema\#> .

@prefix xsd: <http://www.w3.org/2001/XMLSchema\#> .

@ prefix d2rq: <http://www.wiwiss.fu-berlin.de/suhl/bizer/D2RQ/0.1\#> .

@ prefix jdbc: <http://d2rq.org/terms/jdbc/> . map:database a d2rq:Database;

d2rq:jdbcDriver "com.mysql.jdbc.Driver";

d2rq:jdbcDSN "jdbc:mysql:///ui_repository";

d2rq:username "root";

jdbc:autoReconnect "true"; jdbc:zeroDateTimeBehavior "convertToNull";

\# Table form

map:form a d2rq:ClassMap;

d2rq:dataStorage map:database; d2rq:uriPattern

"form/@@form.id_form|urlify@@";

d2rq:class vocab:form;

d2rq:classDefinitionLabel "form";

map:form label a d2rq:PropertyBridge; d2rq:belongsToClassMap map:form; d2rq:property rdfs:label; d2rq:pattern"form \#@@form.id_form@@"; map:form_id_form a d2rq:PropertyBridge;

d2rq:belongsToClassMap map:form;

d2rq:property vocab:form_id_form; d2rq:propertyDefinitionLabel "form id_form"; d2rq:column "form.id_form";

map:form_nama a $\overline{\mathrm{d}} 2 \mathrm{rq}$ :PropertyBridge; d2rq:belongsToClassMap map:form d2rq:property vocab:form_nama; d2rq:propertyDefinitionLabel "form nama";

d2rq:column "form.nama";.

map:form_url a d2rq:PropertyBridge;

d2rq:belongsToClassMap map:form;

d2rq:property vocab:form_url;

d2rq:propertyDefinitionLabel "form url";

d2rq:column "form.url";.

map:form_path_code a d2rq:PropertyBridge; d2rq:belongsToClassMap map:form; d2rq:property vocab:form_path_code; d2rq:propertyDefinitionLabel "form path_code"; d2rq:column "form.path_code";. map:form_file a d2rq:PropertyBridge; d2rq:belongsToClassMap map:form; d2rq:property vocab:form_file; d2rq:propertyDefinitionLabel "form file";

d2rq:column "form.file"; .

\# Table komponen

map:komponen a d2rq:ClassMap;

d2rq:dataStorage map:database;

d2rq:uriPattern "komponen/@@komponen.id_komponen|urlify@@";

d2rq:class vocab:komponen;

d2rq:classDefinitionLabel "komponen";

map:komponen_label

d2rq:PropertyB $\overline{\text { ridge; }}$

d2rq:belongsToClassMap map:komponen;

d2rq:property rdfs:label;

210 BRILIANT: Jurnal Riset dan Konseptual

Volume 4 Nomor 2, Mei 2019 
d2rq:pattern "komponen \#@@komponen.id_komponen@@";

map:komponen_id_komponen a d2rq:PropertyBridge; d2rq:belongsToClassMap map:komponen;

d2rq:property vocab:komponen_id_komponen; d2rq:propertyDefinitionLabel "komponen id_komponen"; d2rq:column "komponen.id_komponen"; .

map:komponen_id_form a d2rq:PropertyBridge; d2rq:belongsToClassMap map:komponen; d2rq:property vocab:komponen_id_form; d2rq:propertyDefinitionLabel "komponen id_form"; d2rq:column "komponen.id_form"; .

map:komponen_nama_komponen a

a $\quad$ 2rq:PropertyBridge;

d2rq:belongsTo-ClassMap map:komponen;

d2rq:property vocab:komponen_nama_komponen; d2rq:propertyDefinitionLabel "komponen nama_komponen"; $\overline{\mathrm{d}} 2 \mathrm{rq}$ :column "komponen.nama_komponen";

map:komponen_id a

d2rq:PropertyBridge;

d2rq:belongsToClassMap map:komponen;

d2rq:property vocab:komponen_id;

d2rq:propertyDefinitionLabel "komponen id";

d2rq:column "komponen.id";.

Gambar 4. Hasil RDF Mapping

Mapping dalam penelitian ini ditulis sesuai dengan template oleh D2R Mapping Language. Map: database digunakan untuk melakukan koneksi database ui_repository. Map: ClassMap berfungsi sebagai deskripsi kolom pada database. Property Bridge berfungsi untuk menginisialisasi setiap kolom pada tabel. Vocab: yaitu bagian dari property bridge yang digunakan sebagai variabel dalam SPARQL.

Hasil dari proses mapping tersebut menghasilkan sebuah file RDF dalam format Turtle (.ttl). Setelah itu, database pada SQL dapat diakses melalui query SPARQL dengan menggunakan tool D2RQ. Pada gambar 5. menjelaskan tentang pendekatan UI discovery dengan RDF mapping.

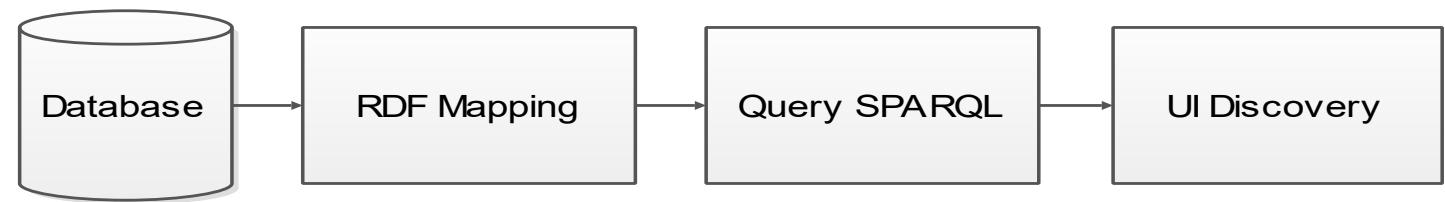

\section{Gambar 5. Pendekatan RDF Mapping}

Setelah melakukan proses mapping, user dapat mengakses data hasil konversi dari model relasional ke RDF menggunakan D2R Server melalui browser (Chen, Zhao, \& Zhang, 2013).

\section{SPARQL}


SPARQL merupakan bahasa query yang digunakan untuk data RDF (Shao, 2011). Pada tahun 2004, RDF Data Access Working Group (bagian dari Semantic Web Activity) merilis konsep kerja publik pertama dari bahasa query untuk RDF, yang disebut SPARQL (Consortium., 2003). Sintaks dalam query SPARQL yaitu select, where, dan from. Penelitian ini menggunakan tiga variabel yaitu nama form, URL, dan code. Penulisan variable diawali dengan tanda tanya (?) pada bagian select. Sintaks where digunakan untuk memilih field yang akan menjadi objek discovery. Sintaks selanjutnya yaitu from yang berfungsi untuk menentukan tabel yang datanya akan diambil. Pada gambar 6 . mengimplementasikan penulisan query SPARQL pada proses discovery.

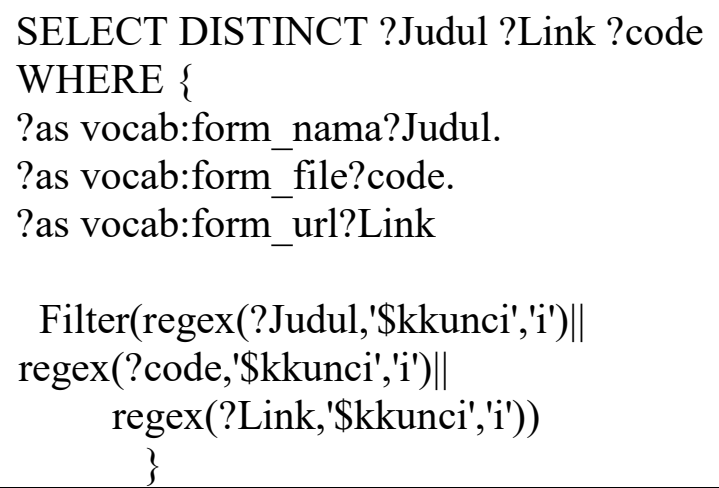

Gambar 6. Penulisan Query SPARQL

\section{HASIL DAN PEMBAHASAN}

Skenario awal pada penelitian yaitu proses pencarian data interface repository pada menu pencarian data. Kata kunci yang digunakan berupa nama form. Pada tahap ini dilakukan proses pencarian data yang proses pencariannya hanya berdasarkan nama form yang tersimpan pada interface repository dan hasilnya berupa nama form yang mengandung unsur kata yang dijadikan kata kunci oleh user. Pada tahap selanjutnya yaitu proses pencarian detail, pada proses ini pencariannya berdasarkan nama form atau metadata yang tersimpan pada repository.

Uji coba sistem ini meliputi percobaan pencarian query data dalam interface repository. Nilai precision dan recall akan menunjukkan nilai relevansi dokumen yang ditemukan melalui proses discovery. Pengujian dilakukan dengan menggunakan 30 data form yang ada di bidang akademik sistem informasi pondok pesantren. Hasil uji coba perhitungan nilai recall, precision, dan accuracy pada 20 query yang telah diuji pada tahap pencarian data dan pencarian detail memiliki hasil dengan rata-rata seperti yang ditunjukkan pada tabel 1 .

Tabel 1. Hasil Uji Coba

\begin{tabular}{|l|l|l|l|}
\hline & Recall & Precision & Accuracy \\
\hline $\begin{array}{l}\text { Pencarian } \\
\text { Data }\end{array}$ & $95 \%$ & $95 \%$ & $100 \%$ \\
\hline $\begin{array}{l}\text { Pencarian } \\
\text { Detail }\end{array}$ & $90 \%$ & $95 \%$ & $100 \%$ \\
\hline
\end{tabular}

212 BRILIANT: Jurnal Riset dan Konseptual Volume 4 Nomor 2, Mei 2019 
Pada hasil uji coba yang telah dilakukan berdasarkan skenario sebelumnya dapat diketahui bahwa terdapat perbedaan antara pencarian kata string-matching yang diinputkan oleh user pada UI discovery. Dengan menggunakan 20 keyword uji coba pada pencarian data dan pencarian detail pada interface repository telah menunjukkan perbandingan nilai akurasi. Perbedaan nilai akurasi disebabkan karena terdapat beberapa analisa pada pencarian detail ada beberapa dokumen tidak relevan yang ditemukan dan terjaring query, sehingga pada pencarian data menunjukkan hasil yang lebih relevan dan menunjukkan kemampuan sistem lebih baik.

\section{KESIMPULAN}

Berdasarkan percobaan yang telah dilakukan, RDF Map digunakan sebagai pendekatan ontologi dan perantara dalam mengakses data pada database relational. Perbedaan antara pencarian data dan pencarian detail terlihat dengan perbedaan query yang dimasukkan pada proses pencarian. Pada tahap pencarian data interface, query yang terjaring hanya dengan berdasarkan nama form, sedangkan pada tahap pencarian detail, query yang terjaring pada sistem tidak hanya nama form saja, melainkan semua query yang tersimpan dalam database. Berdasarkan perhitungan uji coba yang telah dilakukan dengan dua model pencarian yakni pencarian data dan pencarian detail dengan memasukkan 30 data dan 20 query yang telah diuji pada masing-masing model pencarian. Pada tahap pencarian data memperoleh nilai recall $95 \%$, precision $95 \%$ dan accuracy $100 \%$, namun pada pencarian detail didapatkan nilai recall $95 \%$, precision $90 \%$ dan accuracy $100 \%$. Perbedaan tersebut diperoleh karena pada pencarian detail ada beberapa dokumen tidak relevan yang ditemukan dan terjaring query, sehingga pada pencarian data menunjukkan hasil yang lebih relevan dan menunjukkan kemampuan sistem lebih baik.

\section{SARAN}

Dari penelitian yang telah dilakukan, ada beberapa hal yang perlu dikembangkan yaitu menambahkan tahap pengerjaan sistemnya dengan metode indexing terhadap hasil pencarian menggunakan teknik pembobotan agar mendapatkan hasil pencarian yang lebih relevan, dan menggunakan standarisasi OWL dalam penulisan deskripsi dan persamaan kata sehingga proses discovery menjadi lebih lebih mudah.

\section{DAFTAR RUJUKAN}

Barber, R. E., \& Lucas, H. C. (1983). System response time operator productivity and job satisfaction. Communications of the ACM, 26(11), 972-986. https://doi.org/10.1145/182.358464

Chen, Y., Zhao, X., \& Zhang, S. (2013). Publishing rdf from relational database based on d2R improvement. WSEAS Transactions on Information Science and Applications, 10(8), 241-248.

Choudhary, V. (2007). Software as a Service : Implications for Investment in So $\mathrm{ftware}$ Development The Paul Merage School of Business. Proceedings of the 40th Hawaii International Conference on System Sciences, 40(7), 1-10. 
https://doi.org/10.1109/HICSS.2007.493

Consortium., A. J. U. (2003). The Unicode standard. Addison-Wesley 2003 pp: 1462.

Dan R. Olsen, J. (1992). User Interface Management Systems: Models And Algorithms. San Mateo, California: Morgan Kaufmann Publishers.

Enderle, G., \& Duce, D. (n.d.). User Interface Management Systems (G. E. Pfaff, ed.). The European Association for Computer Graphics.

Fauzan, A. C., Sarno, R., \& Ariyani, N. F. (2018). Structure-based ontology matching of business process model for fraud detection. Proceedings of the 11th International Conference on Information and Communication Technology and System, ICTS 2017, 2018-Janua, 221-225. https://doi.org/10.1109/ICTS.2017.8265674

Fauzan, A. C., Sarno, R., Yaqin, M. A., \& Jamal, A. (2017). Extracting Common Fragment Based on Behavioral Similarity Using Transition Adjacency Relations For Scalable Business Processes. International Conference on Information \& Communication Technology and System (ICTS), 131-136.

Gómez-pérez, A., Corcho, O., \& Madrid, U. P. De. (2002). for the Semantic Web. 4.

Green, M. (1985). The University of Alberta user interface management system. SIGGRAPH Comput. Graph., 19(3), 205-213. https://doi.org/10.1145/325165.325286

Knublauch, H., Fergerson, R. W., Noy, N. F., \& Musen, M. A. (2004). The Protege OWL Plugin: An Open Development Environment for Semantic Web Applications. 229-230.

Kumar, K. V. K. M. (2014). Software as a Service for Efficient Cloud Computing. 2319-2322.

Patel, C., Supekar, K., Lee, Y., \& Park, E. K. (2003). OntoKhoj : A Semantic Web Portal for Ontology Searching, Ranking and Classification. 58-61.

Shao, Q. (2011). Towards effective and intelligent multi-tenancy SaaS. (May).

Yaqin, M. A., Sarno, R., \& Fauzan, A. C. (2017). Scalability measurement of business process model using business processes similarity and complexity. International Conference on Electrical Engineering, Computer Science and Informatics (EECSI), 4(September), 306-312. https://doi.org/10.11591/eecsi.4.1033 